\title{
Effects of orienting tasks and instructions about associative structure on free recall and clustering
}

\author{
ROBERT E. TILL, CARROLL D. JOHNSTON, and JAMES J. JENKINS \\ University of Minnesota, Minneapolis, Minnesota 55455
}

\begin{abstract}
Six groups of subjects, in a 2 by 3 design, performed orienting tasks during the presentation of a randomized list of nonadjacent associative pairs. Groups performed one of three tasks: rhyming, pleasantness rating, or "taking dictation" (control). On the other dimension, groups were told about the associative structure and its potential facilitation of recall at one of two times: before hearing the list, or after hearing it. All subjects were forewarned of the recall test. Amount of recall and associative clustering were significantly lower for the rhyming groups than for either the pleasantness rating groups or the control groups. No difference was obtained as a function of when groups were told about the associative structure. The nature of the orienting task appears to be far more important than intention to recall and knowledge about the list structure.
\end{abstract}

Studies by Hyde and Jenkins $(1969,1973)$ and Johnston and Jenkins (1971) explored the effects of orienting tasks on associative clustering in free recall. Their subjects performed designated tasks during the presentation of lists of words comprised of highly associated pairs. Recall and associative clustering were measured as a function of the task performed by subjects.

Hyde and Jenkins (1969) were concerned with the queston of where organization might occur in the input-storage-output model of memory (cf. Melton, 1963). It had been assumed by Jenkins and Russell (1952) that organization in recall is primarily a mediational phenomenon taking place during recall itself. According to this view, once a word is recalled, it acts as an auxillary stimulus to help elicit its associate. However, the findings of Hyde and Jenkins $(1969,1973)$ and Johnston and Jenkins (1971) did not support such

Preparation if this paper was supported in part by the Center for Research in Human Learning at the University of Minnesota. The Center is supported by grants from the National Science Foundation (GB 17590), the National Institute of Child Health and Human Development (HD 01136 and HD 00098), and the Graduate School of the University of Minnesota. Further support was received from the National Institute of Mental Health in the form of a fellowship to the second author (1-F01-MH-43, 804).

The order of authorship was determined by the flip of a coin Reprint requests should be sent to James J. Jenkins, Center for Research in Human Learning, 205 Elliott Hall, University of Minnesota, Minneapolis, Minnesota $\mathbf{5 5 4 5 5}$ an interpretation of organization in recall. All their groups were given the same instructions at the time of recall, yet the groups exhibited marked differences in both recall and percentage of clustering. Groups who performed a nonsemantic orienting task (e.g., subjects wrote a word that rhymed with each of the stimulus words) showed less recall and clustering than the intentional learning control groups. Groups who performed a semantic task (e.g., subjects judged the pleasantness of the meaning of each stimulus word) produced about the same level of recall and clustering as the control groups. These results suggest that the groups were unequal with regard to organization before the recall process began.

In order to provide an optimal situation for determining the extent to which clustering may be attributable to mediation at the time of recall, the present study incorporated instructions to subjects about the associative structure of the list. Six groups were studied: two "dictation" control groups (subjects merely wrote down each stimulus word), two pleasantness rating groups, and two rhyming groups. These rhyming groups were especially important for allowing us to observe the effect of instruction about associative structure on recall and clustering because groups with such a task would otherwise be expected to perform poorly in both respects. It was hypothesized 
that groups performing the pleasantness rating task would not differ in recall or clustering from the "dictation" control groups. The groups performing the rhyming task were expected to show markedly less recall and clustering than the control groups and the pleasantness rating groups despite the instructions about associative structure.

Emphasizing the input stage, Slamecka (1968) suggested that subjects acquire individual words and some general representation of the structure of the list. Hyde and Jenkins (1969) reasoned that he must then argue that the groups who know that they will have to recall the words should have superior organization in recall. However, their results showed no consistent difference within the same tasks across the intentionality variable. That is, incidental and intentional groups did not differ in recall or clustering. Similar results were obtained by Johnston and Jenkins (1971). These findings indicate that clustering differences do not result from differences in intention to learn during input.

A secondary variable was studied in the present experiment with regard to Slamecka's (1968) claim. That is, subjects were informed about the associative structure of the list at one of two times: immediately before they heard the list (before-condition) or immediately after they heard the list (after-condition). No compelling evidence seems to favor either condition at recall, but Slamecka's reasoning suggests that subjects who knew about the associative structure of the list beforehand would have an advantage in terms of organization that might be reflected in recall and clustering. Although earlier studies showed that intention to learn did not lead to an advantage over the incidental condition, perhaps knowledge about the list structure would be important. While subjects in the before condition and after condition all had the possibility of mediation during recall, only the before condition could encode a general represenation of the list structure from the beginning of the list presentation.

\section{METHOD}

\section{Subjects}

All subjects were students in an introductory psychology course at the University of Minnesota. Assignment of subjects to groups was nonsystematic, and experimental conditions were randomly assigned to groups. Six groups were tested in a 2 by 3 design with a total of 139 subjects. On the task dimension, groups were assigned one of the three orienting tasks: rhyming, pleasantness rating, or "taking dictation." On the instructional dimension, groups performed in either the before condition or the after condition.

\section{Apparatus and Materials}

A tape recorder was used to present a list of words to groups of subjects. The subject performing the rhyming task wrote each rhyme response on a separate page of an individual response booklet. The subjects performing the pleasantness rating task were given answer sheets divided into two columns for indicating a "pleasant" or "unpleasant" rating. The subjects in the "dictation" control groups merely wrote down each stimulus
Table 1 Means and Standard Deviations for Opportunities
to Cluster and Percentage of Clustering

\begin{tabular}{|c|c|c|c|c|}
\hline \multirow{2}{*}{$\begin{array}{c}\text { Instructional } \\
\text { Condition }\end{array}$} & & \multicolumn{3}{|c|}{ Task } \\
\hline & & Rhyming & Pleasantness & Control \\
\hline \multicolumn{5}{|c|}{ Before Condition } \\
\hline $\begin{array}{l}\text { Opportunities } \\
\text { to Cluster }\end{array}$ & $\begin{array}{l}\text { Mean } \\
\text { SD }\end{array}$ & $\begin{array}{l}6.00 \\
2.06\end{array}$ & $\begin{array}{l}9.28 \\
1.90\end{array}$ & $\begin{array}{l}9.92 \\
1.14\end{array}$ \\
\hline \multirow[t]{2}{*}{$\begin{array}{l}\text { Percentage of } \\
\text { Clustering }\end{array}$} & $\begin{array}{l}\text { Mean } \\
\text { SD }\end{array}$ & $\begin{array}{l}29.5 \\
29.6\end{array}$ & $\begin{array}{l}79.6 \\
20.1\end{array}$ & $\begin{array}{l}75.8 \\
22.8\end{array}$ \\
\hline & $\mathbf{N}$ & 27 & 21 & 24 \\
\hline \multicolumn{5}{|l|}{ After Condition } \\
\hline $\begin{array}{l}\text { Opportunities } \\
\text { to Cluster }\end{array}$ & $\begin{array}{l}\text { Mean } \\
\text { SD }\end{array}$ & $\begin{array}{l}6.25 \\
2.03\end{array}$ & $\begin{array}{l}8.87 \\
2.40\end{array}$ & $\begin{array}{l}9.65 \\
1.78\end{array}$ \\
\hline \multirow[t]{2}{*}{$\begin{array}{l}\text { Percentage of } \\
\text { Clustering }\end{array}$} & $\begin{array}{l}\text { Mean } \\
\text { SD }\end{array}$ & $\begin{array}{l}43.2 \\
32.0\end{array}$ & $\begin{array}{l}86.9 \\
15.0\end{array}$ & $\begin{array}{l}78.9 \\
23.1\end{array}$ \\
\hline & $\mathrm{N}$ & 24 & 23 & 20 \\
\hline
\end{tabular}

word on a separate page of a response booklet as the word was presented. At the end of a presentation, all answer sheets were collected, and subjects were given a sheet of paper for recall.

The list of stimulus items, which was identical to the list used by Johnston and Jenkins (1971), contained a total of 28 words. The first two and the last two words in the list were fillers which had less than .03 associative relation with each other or with any other word in the list. The remaining 24 words consisted of 12 highly associated pairs of words. The range of intrapair associative strengths for college students varied from .369 to .729 with a mean of .619 (Palermo \& Jenkins, 1964). ${ }^{1}$ All associative strengths between words in the list except intrapair strengths were less than .03 .

The order of presentation of the words was randomized with the restriction that no member of an associative pair was presented immediately adjacent to the other. The words were selected to meet two additional criteria: (a) none of them rhymed with any other word in the list, and (b) there were common words in English that would rhyme with them.

\section{Procedure}

The words were presented at the rate of one word every $5 \mathrm{sec}$. Each group was instructed before the list presentation as to how to perform the assigned task. Furthermore, all subjects were instructed that they would have to recall as many of the words as possible following the presentation and that the order of recall was not important.

The three groups in the before condition were given additional instructions prior to the list presentation. They were told that the list would contain pairs of words "that would seem to go together" although pair members would not occur consecutively. The subjects were told that if they kept this fact in mind, it would help them remember more of the words. The three groups in the after condition were given this same instruction but only after the list presentation and just before the recall period. During recall, subjects were required to list the words in a column as they were remembered. All subjects were given 5 min for recall.

\section{RESULTS}

The results are reported in Table 1 . Means and standard deviations are presented for both variables: opportunities to cluster and percentage of clustering. An opportunity to cluster, which is synonymous with the term "category" used by Cohen (1966), is defined by 
the occurrence of one of the members of an associative pair during recall. The subsequent appearance of the other member of the pair was not counted as an additional opportunity for clustering. The percentage of clustering measure was the same as the one used in the previous studies, i.e., the ratio of clusters to opportunities to cluster. The data for the two variables were analyzed independently using a two-way analysis of variance.

The analysis on the opportunities to cluster indicated statistical significance on the task dimension $[F(2,133)=$ $47.03, \mathrm{p}<.001]$. No difference in opportunities to cluster was found on the other dimension (time of instruction about associative structure) $[\mathrm{F}(1,133)=.18$, n.s.]. The interaction was nonsignificant $[F(2,133)=$ .37 , n.s.]. Since the instructional variable was nonsignificant and no interaction was obtained, data were pooled across the two levels of the instructional variable. Individual comparisons were then made between the clustering opportunities for the three resulting groups. Clustering opportunities for the rhyming task group were significantly lower than the number of opportunities for the pleasantness rating group $[\mathrm{F}(1,133)=117.59, \mathrm{p}<.001]$, and lower than the opportunities for the control group $[F(1,133)=$ 181.01, $\mathrm{p}<.001]$. Clustering opportunities for the pleasantness rating group were found to be slightly lower than the number of opportunities for the control group; the difference achieved marginal significance, $[F(1,133)$ $=6.22, \mathrm{p}<.05]$.

The analysis on the percentage of clustering indicated statistical significance on the task dimension $[F(2,133)=$ 48.93, $\mathrm{p}<.001]$. No difference in percentage of clustering was obtained on the instructional dimension $[F(1,133)=3.39$, n.s. $]$. The interaction was nonsignificant $[F(2,133)=.62$, n.s. $]$. Again, the data were pooled across the two levels of the instructional variable. Individual comparisons were made between the percentages of clustering for the three groups. The clustering percentage for the rhyming task group was significantly lower than the percentage for the pleasantness rating group $[F(1,133)=179.23, p<.001]$, and lower than the percentage for the control group $[F(1,133)=$ $134.33, \mathrm{p}<.001]$. The control group and pleasantness rating group did not differ in clustering percentage $[\mathrm{F}(1,133)=2.94$, n.s. $]$.

An a posteriori comparision of the two rhyming task groups was made to see if clustering was facilitated in this condition by recent instruction about the associative structure of the list. The Scheffé contrast on the clustering percentages for the before condition and after condition (rhyming task groups) failed to achieve the critical value for significance.

\section{DISCUSSION}

The results of the experiment furnish repeated evidence that recall and clustering are heavily dependent on the nature of the orienting task. Groups performing a semantic task (pleasantness rating) did not differ in amount of associative clustering from control groups ("taking dictation"). In amount of recall, the control groups had only a slightly greater number of opportunities to cluster than the pleasantness rating groups.

Groups performing the nonsemantic task (rhyming) showed less recall and clustering than either the control groups or the semantic task groups. Earlier studies rejected explanations of this result based on stimulus fractionation (Johnston \& Jenkins, 1971), and amount of rehearsal time or effort (Walsh \& Jenkins, 1973). The poor performances of the nonsemantic task groups in this experiment were obtained despite instructions concerning recall and the associative structure of the list. Apparently, the nature of the orienting task is far more important for recall and clustering than intentionality or knowledge of a retrieval system based on the list structure.

The instructional variable had little effect in this experiment. For groups of subjects performing the same task, those in the before condition did not differ in recall or clustering from those in the after condition. If subjects benefited from knowing about the associative structure beforehand, it was not manifested in recall and clustering scores. This is consistent with the lack of difference often reported for the more general intention-to-learn variable.

It is interesting to ask what one can do to boost the performance of the rhyming task group. Walsh and Jenkins (1973) required subjects to perform an additional task within the same (unchanged) length of time. Of particular interest are the findings for their groups in which a semantic task was assigned in addition to a nonsemantic one. They showed that rather than overloading the subjects, the additional semantic task resulted in a large and significant increase in recall. It is clear that subjects can do something in addition to the rhyming task to improve their performance, but instructions which presumably create an intention to learn and which reveal partial information about the list structure do not engage subjects in any particular and efficient processing activity.

\section{REFERENCES}

Cohen, B. H. Some-or-none characteristics of coding behavior Journal of Verbal Learning and Verbal Behavior, 1966, 5 , 182-187.

Hyde, T. S., \& Jenkins, J. J. The differential effects of incidental tasks on the organization of recall of a list of highly associated words. Journal of Experimental Psychology, 1969, 82, 472-481.

Hyde, T. S., \& Jenkins, J. J. Recall for words as a function of semantic, graphic and syntactic orienting tasks. Journal of Verbal Learning and Verbal Behavior, 1973, 12, 471-480.

Jenkins, J. J., \& Russell, W. A. Associative clustering during recall. Journal of Abnormal and Social Psychology, 1952, 47, 818-821.

Johnst on, C. D., \& Jenkins, J. J. Two more incidental tasks that differentially affect associative clustering in recall. Journal of Experimental Psychology, 1971, 89, 92-95.

Melton, A. W. Implications of short-term memory for a general theory of memory. Journal of Verbal Learning and Verbal Behavior, 1963, 2, 1-21.

Palermo, D. S., \& Jenkins, J. J. Word association norms: Grade school through college. Minneapolis: University of Minnesota Press, 1964.

Slamecka, N. J. An examination of trace storage in free recall. Journal of Experimental Psychology, 1968, 76, 504-513.

Walsh, D. A., \& Jenkins, J. J. Effects of orienting tasks on free-recall in incidental learning: Difficulty, effort and process explanations. Journal of Verbal Learning and Verbal Behavior, $1973,12,481-488$.

\section{NOTE}

1. Also taken from D. G. Doren's unpublished norms using Palermo-Jenkins associative norm responses as stimulus words, 1968.

(Received for publication October $7,1974$. 